\title{
Reply to: methodological inconsistencies define thermal bottlenecks in fish life cycle
}

\author{
Flemming Dahlke ${ }^{1,3}$ (D) Martin Butzin ${ }^{1} \cdot$ Sylke Wohlrab ${ }^{1} \cdot$ Hans-Otto Pörtner ${ }^{1,2}$
}

Received: 15 October 2021 / Accepted: 17 January 2022 / Published online: 17 February 2022

(c) The Author(s) 2022

\begin{abstract}
The identification of biological pattern is often complicated by the lack of methodologically consistent data with broad geographic coverage, especially when considering functional characteristics of organisms that differ greatly in body size and morphology. In our study (Dahlke et al. 2020), we addressed the problem of data scarcity by using different types of observational and experimental data together with statistical (phylogenetic) data imputation, and by placing our analysis into the context of a physiological concept, which provides a mechanism-based explanation for the observed pattern (ontogenetic shift in thermal tolerance of fish) and with respect to transition from sublethal to lethal thresholds. Here, we show with comparative examples that our results were not affected by the use of methodologically inconsistent data.
\end{abstract}

In their comment, Pottier et al. questioned some of our methods and results, including the observation that the heat tolerance limit of reproductive (spawning) fish and embryos is on average $\sim 10{ }^{\circ} \mathrm{C}$ lower than that of non-reproductive adults. The critique by Pottier et al. included the claim that our (unconventional) approach for estimating the temperature limits of spawners and embryos (occurrence data, sublethal thresholds and lethal thresholds determined by different methods) systematically underestimated the heat tolerance of these life stages compared to adult fish for which we considered conventional $\mathrm{CT}_{\max }$ and $\mathrm{LT}_{50}$ values previously compiled by Comte and Olden (2017).

We generally agree that the use of different methods and tolerance metrics is not ideal in the strict sense of a comparative analysis, and acknowledge that the description of our analyses was not precise enough for a reader to pick up all details. However, Pottier et

Flemming Dahlke

flemming.dahlke@thuenen.de

1 Helmholtz Centre for Polar and Marine Research, Alfred Wegener Institute, Am Handelshafen 12, 27570 Bremerhaven, Germany

2 University of Bremen, NW 2, Loebener Str, 28359 Bremern, Germany

3 Thuenen Institute of Fisheries Ecology, Herwigstraße 31, 27572 Bremerhaven, Germany 
al. disregarded that we placed our analysis into the context of a physiological concept (i.e., oxygen- and capacity-limited thermal tolerance, OCLTT) that is suitable to explain the observed difference in thermal tolerance between life stages and that also captures the transition from sublethal to lethal thresholds. Dahlke et al. 2020 provided additional data (temperature-dependent development and metabolism) consistent with physiological theory and the observed pattern of life stage specific thermal tolerance. The results and conclusions presented in Dahlke et al. 2020 also agree well with previous analysis of smaller, methodological more consistent data sets (e.g., Rombough 1997). With this line of evidence, we are confident that the results presented in Dahlke et al. 2020 were not significantly biased by the use of different tolerance metrics and variability in experimental protocols applied for species and life stages with often extremely different body sizes, morphologies and husbandry requirements. It is therefore surprising to us that Pottier et al. question the validity of our results without providing a formal analysis.

The illustrations by Pottier et al. imply that the embryo data we used would always fall below conventional $\mathrm{CT}_{\max } / \mathrm{LT}_{50}$ values. While we can demonstrate that this assumption is not entirely correct, we must note that it was not clear from the method text that the embryo data presented in Dahlke et al. 2020 also included $\mathrm{LT}_{50}$ values, such as those extracted from Rombough (1997). These $\mathrm{LT}_{50}$ values were determined based on (statistically significant) regressions and therefore correspond to our definition of the heat tolerance limit of embryos ("temperatures causing statistically significant change in survival relative to the optimum value").

To show that the difference in heat tolerance between embryos and adults was not confounded by methodological inconsistencies, we followed the recommendation of Pottier et al. and compared the main data set of Dahlke et al. 2020 (662 species including criticized embryo data) with a subset of data including only $\mathrm{LT}_{50}$ values for embryos (from Rombough 1997) and available $\mathrm{CT}_{\max } / \mathrm{LT}_{50}$ values for adults of the same species ( 37 species, Fig. 1a). Both data sets indicate a substantial increase in heat tolerance from embryos to adults (Fig. 1a), with a median difference between life stages of $10.96{ }^{\circ} \mathrm{C}$ in the main data set and $10.80^{\circ} \mathrm{C}$ in the data subset (Fig. 1b). A priori, we used the data set compiled by Comte and Olden (2017) to confirm that differences between adult $\mathrm{CT}_{\max }$ values (median $35.8{ }^{\circ} \mathrm{C}, 346$ observations, 246 species) and adult $\mathrm{LT}_{50}$ values (median $35.3^{\circ} \mathrm{C}, 427$ observations, 313 species) are statistically not significant $(\mathrm{P}=0.1633)$, using a generalized additive mixed model to account for the latitudinal origin of species and phylogenetic independence (as described in the supplement of Dahlke et al. 2020).

Furthermore, based on temperature-dependent hatching success (i.e. embryo survival) in polar cod (Boreogadus saida, Fig. 2a) and Atlantic cod, (Gadus morhua, Fig. 2b) from different regions (Dahlke et al. 2016, Dahlke et al. 2017, Dahlke et al. 2018, Laurel et al. 2018) we show that conventional $\mathrm{LT}_{50}$ values differ marginally from the values determined as described in Dahlke et al. 2020. More explicitly, $\mathrm{LT}_{50}$ values determined by nonlinear regression analysis $\left(R^{2}>0.7, P<0.001\right)$ across two populations of $B$. saida $\left(3.41{ }^{\circ} \mathrm{C}, 95 \%\right.$ confidence range: 2.94 to $3.50{ }^{\circ} \mathrm{C}$, Fig. 1c) and four populations of $G$. morhua $\left(9.14{ }^{\circ} \mathrm{C}\right.$, $95 \%$ confidence range: 8.94 to $9.74{ }^{\circ} \mathrm{C}$, Fig. 1d) fall within the range of values determined according to Dahlke et al. (2020) for individual populations (B. saida: 3.0 to $3.5{ }^{\circ} \mathrm{C}, \mathrm{G}$. morhua: 8.0 to $9.5^{\circ} \mathrm{C}$ ). Adult $\mathrm{CT}_{\max }$ values of $B$. saida $\left(14.9\right.$ to $17.1^{\circ} \mathrm{C}$ ) (Drost et al. 2016) and $G$. morhua $\left(21.4\right.$ to $23^{\circ} \mathrm{C}$ ) (Norin et al. 2019) are more than $10^{\circ} \mathrm{C}$ higher compared to embryo $\mathrm{LT}_{50}$ values. 

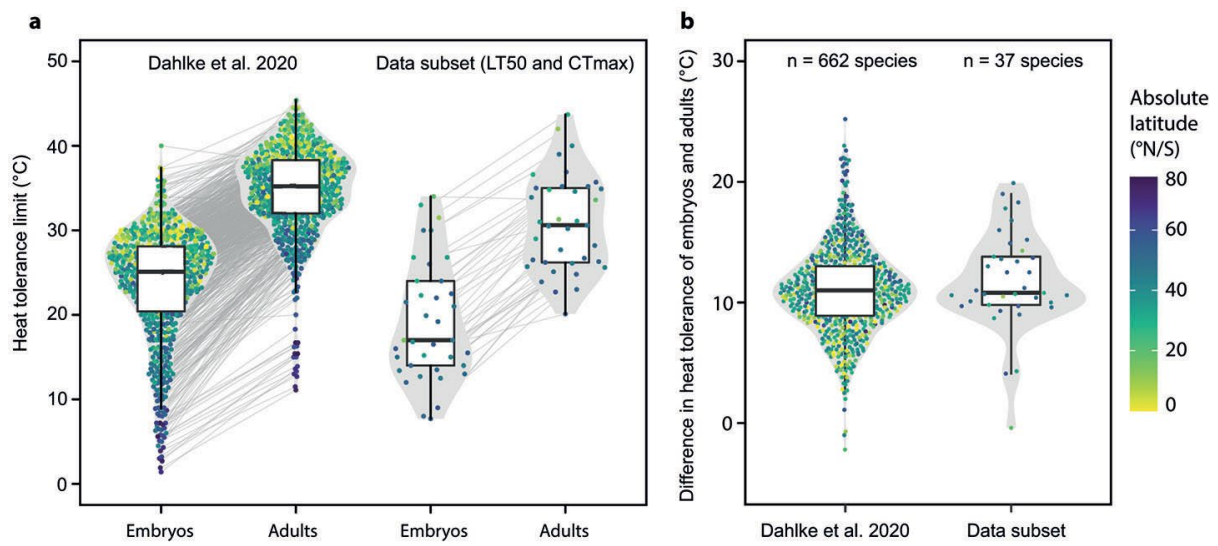

Fig. 1 Comparison of thermal tolerance data used in Dahlke et al. (2020). (a, b) The main data set of upper tolerance limits for embryos and adults (662 species, including criticized tolerance metrics) presented in Dahlke et al. (2020) is compared with a representative subset of data based solely on $\mathrm{LT}_{50}$ and $\mathrm{CT}_{\max }$ methodology [37 species, data from Rombough (1997) and Comte and Olden (2017)]. Individual data points (species) are arranged as kernel density plots, with boxplots indicating interquartile ranges (boxes), medians (horizontal lines) and 5 to $95 \%$ quartiles (whiskers). Colours indicate the latitudinal origin of species. In a, data for embryos and adults of the same species are linked by grey lines. Higher heat tolerance limits of embryos and adults in the main data set compared to the data subset are explained by latitudinal origin and associated thermal regimes. In $\mathbf{b}$, the median difference between the heat tolerance limit of embryos and adults in the main data set is $10.96{ }^{\circ} \mathrm{C}$ and $10.80^{\circ} \mathrm{C}$ in the data subset

As pointed out by Pottier et al., some embryo data originally published in a Japanese series (e.g., Mito 1963) and extracted from a compilation by Motani and Wainwright (2015) correspond to occurrence limits rather than physiological limits as described in our methods. It is important to note that in contrast to terrestrial ectotherms, the distributional limits of aquatic species and life stages often coincide with their physiological temperature limits (Sunday et al. 2012, see also figure S1 in the supplement of Dahlke et al. 2020 for data on spawning fish).

Pottier et al. suggest heartbeat measurements to determine $\mathrm{CT}_{\max }$ values of embryos and provide an example (Del Rio et al. 2019) where eyed-stage embryos of chinook salmon (Oncorhynchus tshawytscha) exhibit heartbeat-based $\mathrm{CT}_{\max }$ values $\left(30^{\circ} \mathrm{C}\right)$ similar or higher than juveniles. Here it is important to note that embryos of fish species (including salmonids) are most heat-sensitive during early embryogenesis prior to the development of the heart and circulatory system (see Rombough 1997). In our study, we considered for this species the embryo $\mathrm{LT}_{50}$ tolerance range $\left(3-15^{\circ} \mathrm{C}\right)$ reported in Rombough (1997), which [consistent with the conclusions of Del Rio et al. (2019)] represents a critical bottleneck in the life cycle of chinook salmon.

Of course, it is difficult to directly compare the temperature limits of spawners observed in the field to the experimentally determined $\mathrm{CT}_{\min / \max }$ values of adults or larvae. However, the agreement we demonstrated between very narrow field and laboratory tolerance limits of spawners (figure S1 in the supplement our paper) confirms that these data are highly relevant for determining the climate change vulnerability of fish species. In this context it is also important to note that the tolerance metric used for spawners is lowered substantially by 

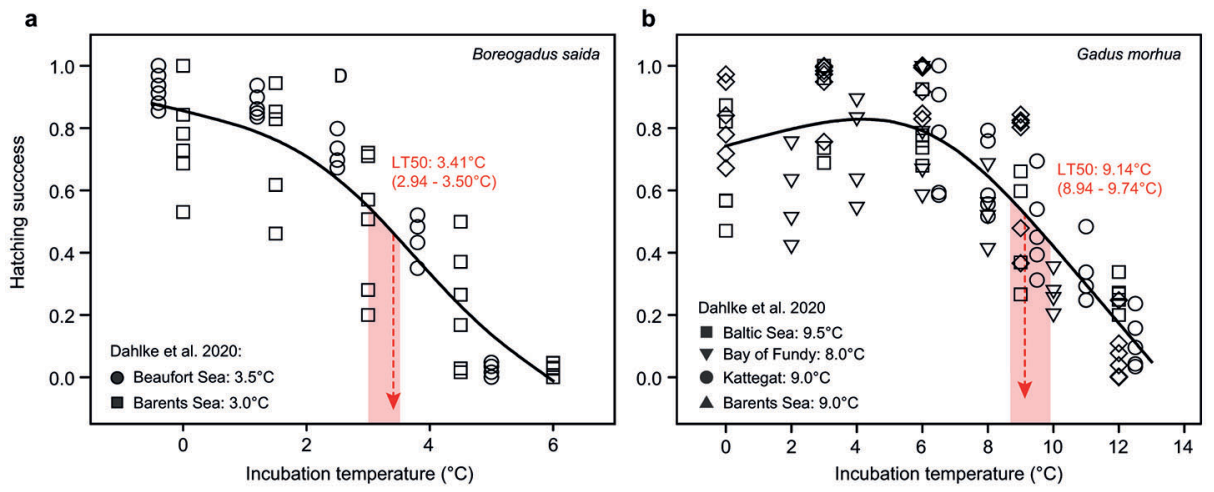

Fig. 2 Hatching success of (a) polar cod (Boreogadus saida) and (b) Atlantic cod (Gadus morhua) is shown as a function of temperature, with different symbols indicating data from independent experiments with different populations. For each species, overall $\mathrm{LT}_{50}$ values (red numbers and arrows) were estimated based on regression analysis (black lines, $\mathrm{R}^{2}>0.7, \mathrm{P}<0.001$ ), with $95 \%$ confidence intervals $(95 \% \mathrm{CI})$ based on posterior parameter estimation (red shading). Overall $\mathrm{LT}_{50}$ values of B. Saida $\left(3.41{ }^{\circ} \mathrm{C}, 95 \% \mathrm{CI}\right.$ : 2.94 to $\left.3.50{ }^{\circ} \mathrm{C}\right)$ and $\mathrm{G}$. morhua $\left(9.14{ }^{\circ} \mathrm{C}, 95 \% \mathrm{CI}: 8.94\right.$ to $\left.9.74{ }^{\circ} \mathrm{C}\right)$ are within the range of values determined for different populations based on the methodology described in Dahlke et al. (2020): B. saida: 3.0 to $3.5^{\circ} \mathrm{C}$; $G$. morhua: 8.0 to $9.5^{\circ} \mathrm{C}$

gonads and gametes including their development and gamete fertility. As a counter example, Pottier et al. cited a study (Auer et al. 2021) showing only a slight decrease in $\mathrm{CT}_{\max }$ of females of a viviparous fish during late gestation. This study does not contradict our results because the effects of elevated temperatures on reproductive performance and fertility were not assessed by Auer et al.. On the contrary, Auer et al. (2021) provide strong support for the physiological framework of our study (OCLTT) which focuses on sub-lethal (performance) constraints as the first line of thermal intolerance (Pörtner 2001). This also concerns gonad development and gamete fertility (Pörtner 2021).

Pottier et al. highlight some recent studies that propose promising means for standardizing CTmin/max-procedures partly based on experiments with Drosophila (Jørgensen et al. 2019, Jørgensen et al. 2021). It is therefore important for us to mention that one of the best examples supporting the ecological relevance of the temperature limit of fertility and reproduction comes from a study with Drosophila species (van Heerwaarden and Sgrò 2021). The study found that $\mathrm{CT}_{\max }$ values of adults are $\sim 10{ }^{\circ} \mathrm{C}$ higher than male fertility limits and egg-to-adult limits. Higher temperature values for $\mathrm{CT}_{\max }$ than reproductive performance may be more universal, in line with our conclusion that sublethal temperature thresholds for reproductive performance characterize narrow tolerance windows representing a critical bottleneck in the lifecycle of fish and possibly other taxa.

Autors' contributions: FD drafted the manuscript and analysed data, SW and HOP revised and edited the manuscript.

Funding: FD and HOP were supported by the Federal Ministry of Education and Research (BMBF grant FZK01LS1604A). SW was supported by the Helmholtz-Institute for Functional Marine Biodiversity at the University of Oldenburg (HIFMB), a collaboration between the Alfred-Wegener-Institute, Helmholtz Centre for Polar and Marine Research, and the Carl-von-Ossietzky University Oldenburg, initially funded by the Ministry for Science and Culture of Lower Saxony (MWK) and the Volkswagen Foundation through the "Niedersächsisches Vorab" grant program (grant number ZN3285). 


\section{Open Access funding enabled and organized by Projekt DEAL.}

Availability of data and material (not applicable).

Code Availability (not applicable).

\section{Declarations}

Conflicts of interest/competing interests: the authors declare not conflict of interest or competing interests.

Ethics approval (not applicable).

Consent to participate: all authors gave consent to participate in this work.

Consent for publication: all authors gave consent for publication.

Open Access This article is licensed under a Creative Commons Attribution 4.0 International License, which permits use, sharing, adaptation, distribution and reproduction in any medium or format, as long as you give appropriate credit to the original author(s) and the source, provide a link to the Creative Commons licence, and indicate if changes were made. The images or other third party material in this article are included in the article's Creative Commons licence, unless indicated otherwise in a credit line to the material. If material is not included in the article's Creative Commons licence and your intended use is not permitted by statutory regulation or exceeds the permitted use, you will need to obtain permission directly from the copyright holder. To view a copy of this licence, visit http://creativecommons.org/licenses/by/4.0/.

\section{References}

Auer SK, Agreda E, Chen A, Irshad M, Solowey J (2021) "Late-stage pregnancy reduces upper thermal tolerance in a live-bearing fish". J Therm Biol 99:103022

Comte L, Olden JD (2017) Climatic vulnerability of the world's freshwater and marine fishes. Nature Climate Change 7(10):718-722

Dahlke FT, Butzin M, Nahrgang J, Puvanendran V, Mortensen A, Pörtner H-O, Storch D (2018) "Northern cod species face spawning habitat losses if global warming exceeds 1.5 C". Sci Adv 4(11):eaas8821

Dahlke FT, Leo E, Mark FC, Pörtner HO, Bickmeyer U, Frickenhaus S, Storch D (2017) "Effects of ocean acidification increase embryonic sensitivity to thermal extremes in Atlantic cod, Gadus morhua". Global change biology 23(4):1499-1510

Dahlke FT, Politis SN, Butts I, Trippel EA, Peck M (2016) Fathers modify thermal reaction norms for hatching success in Atlantic cod, Gadus morhua. J Exp Mar Biol Ecol 474:148-155

Dahlke FT, Wohlrab S, Butzin M, Pörtner H-O (2020) "Thermal bottlenecks in the life cycle define climate vulnerability of fish" Science 369(6499):65-70

Del Rio AM, Davis BE, Fangue NA, Todgham AE (2019) "Combined effects of warming and hypoxia on early life stage Chinook salmon physiology and development". Conservation physiology 7(1):coy078

Drost H, Lo M, Carmack E, Farrell A (2016) Acclimation potential of Arctic cod (Boreogadus saida) from the rapidly warming Arctic Ocean. J Exp Biol 219(19):3114-3125

Jørgensen LB, Malte H, Overgaard J (2019) "How to assess Drosophila heat tolerance: unifying static and dynamic tolerance assays to predict heat distribution limits". Funct Ecol 33(4):629-642

Jørgensen LB, Malte H, Ørsted M, Klahn NA, Overgaard J (2021) A unifying model to estimate thermal tolerance limits in ectotherms across static, dynamic and fluctuating exposures to thermal stress. Sci Rep 11(1):1-14

Laurel BJ, Copeman LA, Spencer M, Iseri P (2018) "Comparative effects of temperature on rates of development and survival of eggs and yolk-sac larvae of Arctic cod (Boreogadus saida) and walleye pollock (Gadus chalcogrammus)". ICES. Journal of Marine Science 75(7):2403-2412

Mito S (1963) "Pelagic fish eggs from Japanese waters-II Percina". Japanese Journal of Ichthyology 11(1-2):39-6417 
Motani R, Wainwright PC (2015) "How warm is too warm for the life cycle of actinopterygian fishes"? Sci Rep 5(1):1-10

Norin T, Bailey JA, Gamperl AK (2019) "Thermal biology and swimming performance of Atlantic cod (Gadus morhua) and haddock (Melanogrammus aeglefinus)". PeerJ 7:e7784

Pörtner H (2001) Climate change and temperature-dependent biogeography: oxygen limitation of thermal tolerance in animals. Naturwissenschaften 88(4):137-146

Pörtner H-O (2021) Climate impacts on organisms, ecosystems and human societies: integrating OCLTT into a wider context. J Exp Biol 224(Suppl1):jeb238360

Rombough PJ (1997) The effects of temperature on embryonic and larval development. Global Warming: Implications for Freshwater and Marine Fish. C. M. Wood and D. G. McDonald. Seminar Series-Society For Experimental Biology, Cambridge University Press. 61:177-224

Sunday JM, Bates AE, Dulvy NK (2012) Thermal tolerance and the global redistribution of animals. Nature Climate Change 2(9):686-690

van Heerwaarden B, Sgrò CM (2021) Male fertility thermal limits predict vulnerability to climate warming. Nat Commun 12(1):1-11

Publisher's Note Springer Nature remains neutral with regard to jurisdictional claims in published maps and institutional affiliations. 